\title{
Refractory Ocular Behçet's Disease; Outcome of Low Dose Infliximab
}

\author{
Nira Ferdous ${ }^{1,2}$, Md. Nazrul Islam ${ }^{1,3 *}$, Farah Habibur Rahman1, Zahedur Rahman Pannu', Fahid Bin Nazrul', \\ Ashik Uz Zaman ${ }^{1}$, Johannes J. Rasker ${ }^{5}$
}

${ }^{1}$ Modern One Stop Arthritis Care and Research Center ${ }^{\circledR}(M O A C \& R C \circledR)$, Dhaka. ${ }^{2}$ Department of Medicine, MH Samorita Hospital and Medical College. ${ }^{3}$ Department of Rheumatology, Bangabandhu Sheikh Mujib Medical University (BSMMU). ${ }^{4}$ Bangladesh Eye Hospital, Dhaka. ${ }^{5}$ Department of Psychology, Health and Technology, University of Twente, Enschede, the Netherlands.

\begin{abstract}
A 40-year-old woman had been suffering from many symptoms of Behçet's disease (BD) since her childhood without being diagnosed. She had recurrent mouth ulcers and, from the age of 21, vulva ulcers followed by loss of vision due to central retinitis and later also ankle arthritis. At the age of 31, uveitis due to BD was diagnosed. The fact that BD is often not recognized in Bangladesh explains the marked delay in her diagnosis. The initial central retinitis responded well to oral glucocorticoids, azathioprine, and cyclosporine, but in the course of time she became refractory to these agents. Considering her financial constraints, low dose Infliximab $(3 \mathrm{mg} / \mathrm{kg})$ was used and resulted in a remarkable but temporal improvement. She went into remission by using a regimen of $5 \mathrm{mg} / \mathrm{kg}$ with increased interval time.

In this article, the treatment options for ocular involvement in BD patients are summarized.

Conclusions: In countries like Bangladesh, the diagnosis of Behçet's disease can be delayed. The early cooperation of dermatologists and eye surgeons with rheumatologists is necessary. Most cases of resistant ocular BD today can be successfully treated with anti-TNF agents. Promising results are published with other biologics for refractory and multi-resistant cases.
\end{abstract}

Keywords: Refractory Ocular Behçet’s Disease, Low Dose Infliximab

\section{Introduction}

Behçet's disease (Morbus Behçet) is also known as Behçet's syndrome, Behçet-Adamantides syndrome, or Silk Road disease [1]. Behçet's disease (BD) is more common in Turkey, the Middle East, Japan, and countries along the historic Silk Road (an ancient trading route beginning in Japan, going through China, the Far East, central Asia, and Iran, and ending in Turkey), but it can be found worldwide, especially in countries with large numbers of immigrants from those regions [2]. The disease is named after Hulusi Behçet, a Turkish dermatologist who in 1937 described in two of his patients the triad: recurrent aphthous mouth ulcers, recurrent iridocyclitis with hypopyon, and genital ulcerations [3]. Behçet's disease may also affect other organ systems, such as the gastrointestinal system. Next to this triad, the gastrointestinal, musculoskeletal, and neurological systems and sometimes the lungs and heart may be affected [4]. The exact etiology of the disease is still unknown. The fact that there is a clustering of symptoms and that there are regional differences in the expression of the disease suggest that several etiological pathways play a role in Behçet syndrome. From genetic studies, it has become clear that HLA-B51 and other risk factors play a role, $[5,6]$ but the fact that many BD patients do not have HLA-B51, especially in regions where the disease is not frequently seen, makes it clear that other factors also play a role. These same deliberations are true regarding the recent "MHC-I-opathy" concept [7]. The histology shows autoimmune inflammation of small vessels, mainly venules and capillaries, with mononuclear cell infiltration. Treatment is variable and depends on disease severity and organ involvement. When traditional immunosuppressive agents are insufficient for severe and resistant disease, biologicals like tumor necrosis factor $\alpha$ (TNF- $\alpha$ ) inhibitors are an important therapeutic option [10]. Ocular, vascular, neurological, and gastrointestinal involvements are associated with a poor prognosis $[7,8]$. New treatments have improved outcomes, for example, in Ocular BD (OBD), since the use of Infliximab [9]. According to the updated EULAR recommendations for the management of Behçet's syndrome, "any patient with Behçet's syndrome and inflammatory eye disease affecting the posterior segment

Personal non-commercial use only.Rheumatology Research Journal. Copyright (C) 2019. All rights reserved

*Corresponding Author: Md. Nazrul Islam, Professor, Modern One Stop Arthritis Care and Research Center $($ MOAC\&RC®), Dhaka, Email: islam1nazrul@gmail.com, Tel: (+88) 1678112396.

Received: 12 November 2018 ; Accepted: 22 April 2019 
should be on a treatment regimen such as azathioprine, cyclosporine-A, interferon-alpha, or tumor necrosis factor-alpha (TNF- $\alpha$ ) antagonists" [11]. Infliximab appears to be initiated earlier and more often in less severe cases of uveitis in Behçet's syndrome than before, and this may have improved the outcome [12].

The case reported herein is an example of late recognition of uveitis as part of BD in a country outside the silk road and shows the importance of close cooperation between dermatologists, rheumatologists, and eye surgeons. Furthermore, treatment options for OBD are summarized in this article.

\section{Case Report}

A 40-year-old female, normotensive, non-diabetic, mother of three children had been suffering from recurrent attacks of oral ulcers since her childhood. The severity and frequency of them increased when she was 21 years of age (1997), which was ascribed to the positive family history of recurrent oral ulcers ( 9 members). Eventually, a course of oral prednisolone resulted in a marked improvement of the oral ulcers. After 5 years (January 2002), the patient developed non-itchy painful vulvar ulcers with inguinal lymphadenopathy. After 15 days of suffering, she consulted a physician who requested lab tests (full blood count, random blood sugar, Mantoux test, Venereal Disease Research Laboratory test [VDRL], and Treponema Pallidum Hemagglutination test [TPHA]), all of which were normal. Several antibiotics were tried over a period of 10 months without improvement. For that reason, a biopsy was taken from the patient's genital ulcers. Histopathology reported infiltration of chronic inflammatory cells only and no evidence of granuloma or malignant cells. The patient's antinuclear antibody test (ANA), HLA-B27, HLA-B51, and pathergy test were negative. Next she was prescribed a course of prednisolone $(15 \mathrm{mg})$ with tapering over 15 days, which resulted in total healing of the genital ulcers.

In July 2002, the patient noticed some visual impairment, and from January 2003, she saw tiny black shadows while reading and only a half view of the wall clock in her right eye. Her ophthalmologist diagnosed central retinitis and prescribed prednisolone $40 \mathrm{mg} /$ day, tapered by $5 \mathrm{mg}$ every week to $15 \mathrm{mg}$ /day as a maintenance dose over a period of 1 month. With further tapering over several months, the patient improved, but she had lost one line of her vision (6/9, Snellen's chart) in her affected eye. She was in remission for 8 years.

In October 2002, she developed bilateral ankle joint pain and swelling that improved in weeks with ibuprofen. On further query, she said that she had noticed acne-like lesions for about the last 7 years in her upper back and glu- teal region. There was no evidence of venous thrombosis, stroke, or erythema nodosum.

Unfortunately, her situation did not improve. In 2011, she developed pain, redness, floaters, and dimness in both eyes, and ophthalmologic findings were suggestive of severe bilateral intermediate uveitis. This time the ophthalmologist diagnosed her with BD. She was put on oral prednisolone and azathioprine (AZA) with corticosteroid eye drops and mydriatics. Initially she improved, but when the prednisolone was tapered to below $15 \mathrm{mg} / \mathrm{day}$, the disease flared aggressively despite continuing of AZA $2 \mathrm{mg} /$ $\mathrm{kg}$. To treat her ocular flare and for corticosteroid sparing, cyclosporine was added. As there was no satisfactory improvement and progressive loss of vision, the patient was referred to a tertiary center in India for evaluation and management. There, she underwent cataract surgery and anti-glaucoma treatment. Unfortunately, the patient developed a macular hole for which repair surgery was performed. Despite all usual local and systemic measures, the dose of oral prednisolone could not be decreased below 15 $\mathrm{mg} /$ day. In such situation, the uveitis specialist sought the opinion of a rheumatologist regarding the management of this challenging case.

After evaluation, the rheumatologist advised Infliximab (IFX) $5 \mathrm{mg} / \mathrm{kg}$ body weight with a $0,14,45,90,120$ days, and then 3 months interval schedule to control ocular inflammation and overcome corticosteroid induced side effects. Hearing the price (around $\$ 1000 \mathrm{US} /$ dose) the patient became indecisive about taking IFX for a period of time. Methotrexate (MTX) $10 \mathrm{mg}$ weekly was added with prednisolone and, considering the patient's confusion and financial constraints, a dose of $3 \mathrm{mg} / \mathrm{kg}$ body weight of IFX was suggested. After adequate counseling, the patient decided to start the lower IFX dose with an interval of 14 days. Seven days after the 1st infusion, she started feeling well, and the ocular inflammation began to improve, remaining stable for about 3 months. Laboratory tests remained unremarkable. Three doses according to schedule were given without side effects, and the patient continued oral prednisolone $5 \mathrm{mg} / \mathrm{day}$ and MTX $10 \mathrm{mg} /$ week. The posterior uveitis and intermediate uveitis were well controlled. The patient developed anterior uveitis only, and it was controlled with topical steroids. The ocular findings are summarized in Table 1.

After the 4th IFX treatment, signs of uveitis developed again. The IFX dose was increased to $5 \mathrm{mg} / \mathrm{kg}$, and the patient's symptoms improved. She was advised to follow an 8-weekly-dose regimen, but due to financial constraints, the dose schedule became irregular. The 5th, 6th, and 7th doses were given after $3,4.5$, and 16 months, respectively. Then the patient remained in remission for 6 months. 
Table 1. Eye readings during Infliximab treatment

\begin{tabular}{|c|c|c|c|c|c|c|c|c|c|c|c|}
\hline \multirow[t]{2}{*}{ Date } & \multicolumn{2}{|c|}{$\mathbf{A C}$} & \multicolumn{2}{|c|}{ Pseudophakia } & \multicolumn{2}{|c|}{ Vitrous Haze } & \multicolumn{2}{|c|}{ Macula } & \multicolumn{2}{|c|}{ Disc } & \multirow[t]{2}{*}{ Comment } \\
\hline & OD & OS & OD & OS & OD & OS & OD & OS & OD & OS & \\
\hline 21.11 .15 & Quiet & Quiet & + & + & ++ & ++ & Old macular hole & $\begin{array}{c}\text { Resolved } \\
\text { cystoid } \\
\text { macular } \\
\text { edema(CME) }\end{array}$ & Pale & Pale & Vitritis \\
\hline 12.12 .15 & Quiet & Quiet & + & + & ++ & ++ & Old macular hole & Healed CME & Pale & Pale & Slight vitritis \\
\hline 09.01 .16 & Quiet & Quiet & + & + & ++ & ++ & Old macular hole & CME & Pale & Pale & $\begin{array}{c}\text { Resolving Behçet's } \\
\text { Intermediate Uve- } \\
\text { itis but still active } \\
\text { vitritis }\end{array}$ \\
\hline 27.02 .16 & Quiet & Quiet & + & + & ++ & ++ & Old macular hole & Looks normal & Pale & Pale & $\begin{array}{l}\text { Stable Behçet's in- } \\
\text { termediate Uveitis }\end{array}$ \\
\hline 17.04 .16 & Quiet & Quiet & + & + & ++ & ++ & Old macular hole & Looks normal & Pale & Pale & Behçet's Uveitis \\
\hline 15.10 .16 & Quiet & Quiet & + & + & ++ & ++ & Old macular hole & $\begin{array}{l}\text { Macular } \\
\text { oedema }\end{array}$ & & & \\
\hline 13.12 .16 & Quiet & Quiet & + & + & ++ & ++ & Old macular hole & $\begin{array}{l}\text { Epi-retinal } \\
\text { membrane } \\
\text { (ERM) }\end{array}$ & Pale & Pale & $\begin{array}{l}\text { No active Inflam- } \\
\text { mation }\end{array}$ \\
\hline 21.7 .18 & Quiet & Quiet & + & + & + & ++ & Old macular hole & ERM & Pale & Pale & Active vitritis \\
\hline
\end{tabular}

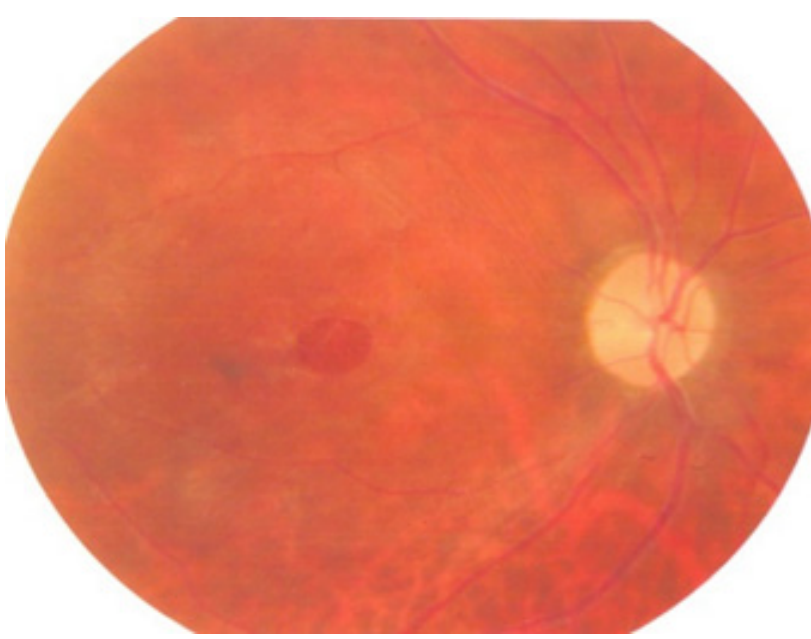

Figure 1. Color Fundus Photograph of right eye shows circular area of deep red color within the macula, suggestive of macular hole. The optic disc is looks pale.

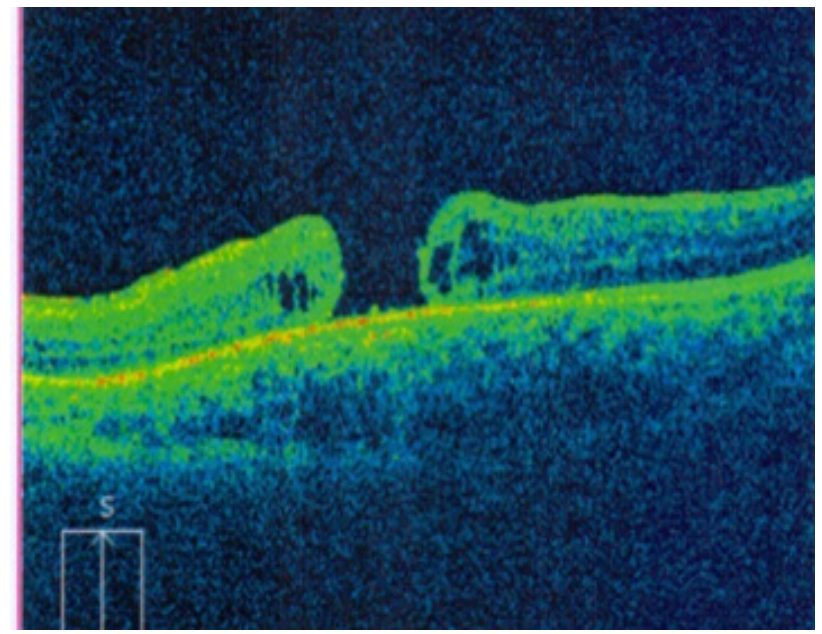

Figure 2. Optical Coherence Tomography through the macula of Right Eye shows gap within the neurosensory retina confirm the diagnosis of macular hole. 


\section{Discussion}

BD usually affects young people aged 20 to 40 years [10 ]. The male-to-female ratio is $3: 1$, [11] and young males have a higher risk and worse prognosis [12]. BD combined with uveitis is rare in Southeast Asia; in a worldwide survey $54 \%$ of cases were from the Middle East, $43 \%$ were from Europe, and only 2\% were from East- and South Asian countries [13]. This multi-systemic disease is diagnosed on the basis of a combination of many clinical findings [15] The symptoms may evolve over many months/ years. Thus, diagnostic delay is not very uncommon [16] A study in Japan showed that the mean time span between initial symptoms and diagnosis was $8.6 \pm 10.1$ years [17]. In the current case, it took about 15 years to make the diagnosis. A possible explanation may be that the symptoms did not present at the same time and that the disease is infrequently diagnosed in Bangladesh.

Eye involvement occurs in 30-70\% of BD patients and is an important cause of blindness, especially at young ages. In general, uveitis in $\mathrm{BD}$ is more common and more severe in men. Frequent forms $(60 \%)$ of ocular involvement in Behçet are relapsing/remitting anterior, intermediate, posterior, or panuveitis in both sexes $[15,16]$. Other ocular problems include retinal vasculitis, infiltrates and hemorrhage, disc hyperemia, and vitreous opacification [17]. The incidence of posterior segment involvement is $50-93 \%$ [17]. Late complications include cataract, iris synechia, glaucoma, retinal vascular occlusion and neo-vascularization, and optic atrophy [18]. In the current case, the patient developed bilateral intermediate uveitis, central retinitis, cataract, and a macular hole. Macular hole is a rare complication in BD (3.4\%); the current patient possibly developed this complication because of her retinal vasculitis $[14,15]$.

\section{Treatment of Ocular BD}

For OBD, systemic or local corticosteroids are advised; when insufficient, systemic immunomodulatory therapy $[8,18,19,23,24]$ and tumor necrosis factor alpha (TNF- $\alpha$ ) inhibitor $[11,22]$. Even with intensive immunosuppressive therapy, however, ocular inflammation may relapse in about $70 \%$ of patients, resulting in permanent loss of vision. The prognosis of OBD has improved significantly over the last decades with the use of immunosuppressives [6,20-26]. Fair results have been described with pulse cyclophosphamide and AZA [27]. In the current case, AZA in combination with corticosteroids failed to control severe uveitis, as did cyclosporine and later MTX before Infliximab was begun.

Several studies have shown good results with anti-TNF-a therapies in uveitis patients [8]. A retrospective study compared IFX with adalimumab (ADA) in 160 patients with noninfectious uveitis (BD in 36\%). Both drugs had equiv- alent efficacies with very good response rates of $95-97 \%$. [20]. In another series, 40 patients with BD-related uveitis (66 eyes) received ADA. During the first 12 months, the number of flares decreased from 200 to 8.5 flares/100 patients/year. Visual acuity and macular thickness improved significantly, and after 12 months retinal vasculitis was healed in 21/22 cases [21].

In an Italian study, 108 patients (188 eyes) with non-infectious intermediate, posterior, or panuveitis treated with ADA or IFX were retrospectively collected; in 87 (80.6\%) patients, uveitis was associated with systemic disease. ADA and IFX were administered in 62 and 46 patients, respectively and had similar long-term effects, not affected by demographic, clinical, or therapeutic (DMARD or not) features [22]. Both VISUAL I and II studies showed excellent efficacy of ADA for idiopathic uveitis in 217 patients, including $16 \mathrm{BD}$ patients [23,24].

Intravitreal ADA has been successfully applied in 4 patients with breakthrough panuveitis in 7 eyes after 7.3 months. Intravitreal ADA warrants further investigation [25].

In an open label study, IFX was superior in reducing attacks of refractory uveitis than conventional therapy [28]. In refractory posterior uveitis, short-term follow-up studies showed the efficacy and safety of TNF- $\alpha$ antagonists [29,30]. Almost all manifestations of BD including acute sight-threatening panuveitis are rapidly suppressed by IFX, and remission is maintained in up to $75 \%$ of patients [29,31].

Literature data differ regarding the number of IFX infusions leading to remission. Of patients receiving 9 infusions, $75-78 \%$ achieved remission in 1 year, and in 50\%, remission lasted a further 12 months; in some studies, only one or less than seven infusions were given $[32,33]$. In another study, after only 6 IFX infusions during 3 months, visual acuity remained improved during 2 years of follow-up [32].

Patients with recent onset disease (18 months) had better visual outcomes with IFX and a milder course; the treatment probably prevented permanent ocular damage [33,34].

In the current case, the patient started with a $3-\mathrm{mg} / \mathrm{kg}$ regimen because she had financial constraints, and the uveitis of her eyes was worsening rapidly. After the first dose of 3 $\mathrm{mg} / \mathrm{kg}$, the patient improved somewhat, and after the $3 \mathrm{rd}$ dose, the uveitis came under control for some time. This course may suggest that a $3-\mathrm{mg} / \mathrm{kg}$ dose 37 can be given to patients who have financial constraints. By using a 5-mg/ $\mathrm{kg}$ regimen, we were able to increase the interval time between the dose schedules.

IFX increases the risk of reactivation of latent tuberculosis and other infections, demyelinating disease, and congestive heart failure;[35] fortunately, the patient reported herein has had no adverse effects to date. 
EULAR advises that any patient with Behçet's syndrome and inflammatory eye disease affecting the posterior segment should be treated with azathioprine (AZA) $(2.5 \mathrm{mg} /$ $\mathrm{kg}$ /day) combined with corticosteroids (level of recommendation 1b) as a first-line choice in OBD involving the posterior segment, while recalcitrant cases with severe eye disease settled as a visual acuity drop $>2$ lines in a 10/10 scale and/or retinal disease (macular involvement or retinal vasculitis) should be treated with either cyclosporine A or Infliximab (IFX) associated with AZA and corticosteroid [8].

\section{Other treatment options for ocular Behçet's disease (OBD)}

\section{Interferon-a-2a (IFN)}

Interferon-a-2a (IFN) showed a partial response in 16 patients with OBD who did not respond to the azathioprine-cyclosporine combination [36]. In a study of 36 patients (67 eyes), 31 (86.1\%) improved with IFN. The mean follow-up was 8.19 years; $21 / 36$ patients discontinued IFN and $76 \%$ of them did not relapse during 5 years after discontinuation [37]. In a series of 32 OBD patients, 30 $(93.7 \%)$ responded to IFN $\alpha 2 \mathrm{a}$ therapy with fewer attacks and improved visual acuity [38]. Weekly administered Pegylated IFNs (IFNa-2a and b) were also effective and well tolerated in five OBD patients [39].

\section{Interleukin-1 inhibitors}

Fabiani et al. studied interleukin-1 inhibitors, anakinra, and canakinumab in a 12-month retrospective study. The number of ocular flares and the frequency of retinal vasculitis decreased significantly at 3 and 12 months. The corticosteroid dosage combination with any DMARD did not improve the outcome [40]. Gevokizumab 30 or $60 \mathrm{mg}$ every 4 weeks iv or sc. on top of stable treatment with immunosuppressives and corticosteroids controlled acute ocular exacerbation in 14/17 patients mostly within 1 week without serious adverse events [41]. In a prospective controlled study of 83 patients (40 gevokizumab, 43 placebo), gevokizumab did not significantly affect the risk of occurrence of ocular exacerbations [42]. Blocking IL-1 might be safer than TNF- $\alpha$ inhibition, especially in areas with endemic tuberculosis [43].

\section{Pulse high-dose intravenous methylprednisolone}

A study of $34 \mathrm{BD}$ patients with posterior uveitis and/or retinal vasculitis showed that adding high-dose iv methylprednisolone pulse therapy for three days to conventional combination therapy resulted in better visual acuity and fewer flares over a 6-month period [44].

\section{Interleukin-6 blockade Toceluzimab (TCZ)}

In 11 patients (20 eyes) with OBD refractory to conventional and biologic immunosuppressive drugs, TCZ $8 \mathrm{mg} /$ $\mathrm{kg}$ yielded rapid and maintained improvement with complete remission in eight patients, but TCZ was withdrawn in two cases because of severe infusion reaction and one due to arthritis impairment; only in 3 patients was TCZ effective for the extraocular manifestations of $\mathrm{BD}$ [45]. TCZ is ineffective on mucocutaneous BD and may cause worsening [43].

\section{Secukinumab}

Secukinumab, binding IL-17A, was not successful in the treatment of $118 \mathrm{BD}$ uveitis patients $[43,46]$.

\section{Ustekinumab}

Ustekinumab, a biological treatment for psoriasis, interferes with IL-17 signaling via IL-23 blockage. The successful use of ustekinumab was described in a 39-year-old Caucasian woman with BD including anterior uveitis in combination with psoriasis and hidradenitis suppurativa. She received $45 \mathrm{mg} \mathrm{sc}$ at weeks 0 and 4 and then every 12 weeks; she remained symptom- and relapse-free for at least 36 months with no need for parallel immunosuppressive drugs [47]. This striking therapeutic success may suggest that this drug be considered as an alternative for other biologic agents [47].

\section{Daclizumab}

Daclizumab is an antibody against $\alpha$-subunit-CD25 of the IL-2 receptor. It has conflicting effects on $\mathrm{OBD}$, none better than the placebo [48]. In other studies, malignancies were detected as well as adverse dermatologic events [43].

\section{Rituximab (RTX)}

Rituximab (RTX) is a CD20 antibody. Although BD is prominently a T-cell driven, B cells play a pathogenetic role. Davatchi et al. conducted a controlled pilot study on 20 OBD patients and showed that after six months, RTX + MTX showed more improvement in eye manifestations than cyclophosphamide-AZA-prednisone. Relapses after some time indicate that continuation of RTX may be desirable. Further studies are needed to find the best treatment regimen [49].

\section{Alemtuzumab}

Alemtuzumab is a humanized monoclonal IgG against CD52 resulting in a long-term depletion of $T$ and $B$ cells and lymphopenia after infusion. In 33 refractory BD patients, all 21 cases with severe OBD went into remission. Relapse was common and seemed to be related to a lower dosage. Severe side effects are common, including thyroid disease, infections, pneumonia, colitis due to clostridium difficile, autoimmune hemolytic anemia, and esophageal carcinoma $[43,50]$.

\section{Conclusions}

- In countries like Bangladesh where BD is seldom seen, clinicians should be aware of OBD with its features that overlap many rheumatologic conditions.

- Multidisciplinary collaboration between rheumatolo- 
gist, dermatologist, and eye physician is important for the diagnosis and management of OBD.

- Most cases of resistant OBD can today be successfully treated with anti-TNF agents. Promising results have been found with other biologics for refractory and multi-resistant cases. Further large studies are needed to fully elucidate and establish the clinical efficacy of these different tools in refractory OBD.

\section{Acknowledgments}

The authors thank the patient for agreeing to the publishing of the findings regarding her disease. We also thank our colleagues at the Eye Department in Dhaka and our Indian colleagues for their highly qualified treatment.

\section{Authorship}

NF, NI: wrote the manuscript; NF, NI, FH, FB, and AU: helped manage the patient's diagnosis and therapy, and prepared the manuscript; NI and JJR: edited the manuscript; NI and ZR: patient's consultants from the Department of Rheumatology and Ophthalmology.

\section{Conflict of Interest}

The authors declare no conflicts of interest 


\section{References}

1. Woźniacka A, Sysa-Jędrzejowska A, Jurowski P , Jabłkowski M, Kot M. Morbus Behçet - a rare disease in Central Europe. Arch Med Sci 2015; 11(6): 1189-96. doi: 10.5114/aoms.2015.56344.

2. Davatchi F, Chams-Davatchi C, Shams H, Shahram F, Nadji A, Akhlaghi M et al. Behcet's disease: epidemiology, clinical manifestations, and diagnosis. Expert Rev Clin Immunol 2017; 13(1):57-65. doi:10.1080/174466 6X.2016.1205486.

3. Behcet $\mathrm{H}$. Uber rezidivierende aphthose, durch ein Virus verursachte Geschwüre am Mund, am Auge und an den Genitalien: Derm Wschr 1937; 36:1152-57.

4. Demirelli S, Degirmenci H, Inci S and Arisoy A. Cardiac manifestations in Behcet's disease. Intractable Rare Dis Res 2015; 4(2):70-75. doi: 10.5582/irdr.2015.01007.

5. International Study Group for Behcet's disease. Criteria for diagnosis of Behcet's disease. Lancet 1990; 335(8697):1078-80. doi: https://doi.org/10.1016/01406736(90)92643-V.

6. Yazici H, Seyahi E, Hatemi G, Yazici Y. Behçet syndrome: a contemporary view. Nat Rev Rheumatol 2018; 14(2):107-19. doi: 10.1038/nrrheum.2017.208.

7. Alibaz-Oner F, Sawalha AH, Direskeneli H. Management of Behçet's disease. Curr Opin Rheumatol 2018; 30(3):238-42. doi: 10.1097/BOR.0000000000000497.

8. Hatemi G, Christensen R, Bang D, Bodaghi B, Celik AF, Fortune $\mathrm{F}$ et al. 2018 update of the EULAR recommendations for the management of Behçet's syndrome. Ann Rheum Dis 2018; 77(6):808-18. doi: 10.1136/annrheumdis-2018-213225.

9. Guzelant G, Ucar D, Esatoglu SN, Hatemi G, Ozyazgan Y, YurdakulS et al. Infliximab for uveitis of Behçet's syndrome: a trend for earlier initiation. Clin Exp Rheumatol 2017; 108(6):86-89.

10. Detanico AB, Brandão ML, Fernandes L F, Camelo CPR, Dos Santos JRS. Aortic thrombosis in a patient with a late diagnosis of Behcet's disease. J Vasc Bras 2015; 14(2):193-96. doi.org/10.1590/1677-5449.0065.

11. Saleh Z, Arayssi T. Update on the therapy of Behcet disease. Ther Adv Chronic Dis 2014; 5(3):112-34. doi: $10.1177 / 2040622314523062$.

12. Kural-Seyahi E, Fresko I, Seyahi N, Ozyazgan Y, Mat C, Hamuryudan, Vet al. The long-term mortality and morbidity of Behcet syndrome: a 2-decade outcome survey of 387 patients followed at a dedicated center. Medicine (Baltimore) 2003; 82(1):60-76. doi: 10.1097/00005792200301000-00006.

13. Leccese P, Yazici Y, Olivieri I. Behcet's syndrome in nonendemic regions. Curr Opin Rheumatol 2017; 29(1):1216. doi: 10.1097/BOR.0000000000000349.

14. Al-Dhibi H, Abouammoh M, Al-Harthi E, Al-Gaeed A, Larsson J, AbboudE,et al. Macular hole in Behçet's disease. Indian J Ophthalmol 2011; 59(5):359-62. doi:

\subsection{3/0301-4738.83611.}

15. Tugal-Tutkun I, Onal S, Altan-Yaycioglu R, HuseyinAltunbas H, Urgancioglu M. Uveitis in Behçet disease: an analysis of 880 patients. Am $\boldsymbol{J}$ Ophthalmol 2004; 138(3):373-80. doi:10.1016/j.ajo.2004.03.022.

16. Duzgun N, Ates A, Aydintug OT, Demir O, Olmez U. Characteristics of vascular involvement in Behçet's disease. Scand J Rheumatol 2006; 35(1):65-68. doi: 10.1080/03009740500255761.

17. BonfioliAA, OreficeF.Behcet'sdisease.Semin Ophthalmol 2005;20(3):199-206.doi:10.1080/08820530500231953.

18. Cunningham ET Jr, Tugal-Tutkun I, Khairallah M, Okada AA, Bodaghi B, Zierhut M. Behçet Uveitis. Ocul Immunol and Inflamm 2017; 25(1):2-6. doi: 10.1080/09273948.2017.1279840.

19. Yalçındağ FN, Yanık Ö, Düzgün N. Efficacy of Infliximab in Patients with Refractory Uveitis Associated with Behçet Disease. J Clin Exp Ophthalmol 2014; 5(1):319. doi:10.4172/2155-9570.1000319.

20. Vallet H, Seve P, Biard L, Baptiste Fraison J, Bielefeld P, Perard L, et al., French Uveitis Network. Infliximab versus adalimumab in the treatment of refractory inflammatory uveitis: a multicenter study from the French Uveitis Network. Arthritis Rheumatol 2016; 68(6):1522-30. doi: 10.1002/art.39667.

21. Fabiani C, Vitale A, Emmi G, Vannozzi L, Lopalco G, Guerriero S, et al. Efficacy and safety of adalimum$a b$ in Behcet's disease-related uveitis: a multicenter retrospective observational study. Clin Rheumatol 2017; 36(1):183-89. doi: 10.1007/s10067-016-3480-x.

22. Fabiani C, Vitale A, Emmi G, Bitossi A, Lopalco G, Sota J, et al. Long-term retention rates of adalimumab and infliximab in non-infectious intermediate, posterior, and panuveitis. Clin Rheumatol 2019; 38(1):63-70. doi: 10.1007/ s10067-018-4069-3.

23. Jaffe GJ, Dick AD, Brézin AP, Nguyen QD, Thorne JE, Kestelyn P, et al. Adalimumab in patients with active noninfectious uveitis. N Engl J Med 2016; 375(10):932-43. doi: 10.1056/NEJMoa1509852.

24. Nguyen QD, Merrill PT, Jaffe GJ, Dick AD, Kurup SK, Sheppard J et al. Adalimumab for prevention of uveitic flare in patients with inactive noninfectious uveitis controlled by corticosteroids (VISUAL II): a multicentre, double-masked, randomised, placebo-controlled phase 3 trial. Lancet 2016; 388(10050):1183-92. doi: 10.1016/S01406736(16)31339-3.

25. Kheir WJ, Mehanna CJ, Abdul Fattah M, Al Ghadban S, El Sabban M, Mansour AM, et al. Intravitreal adalimumab for the control of breakthrough intraocular inflammation. Ocul Immunol Inflamm 2018; 26(8):1206-11. doi: 10.1080/09273948.2017.1335756.

26. Ozyazgan Y, Ucar D, Hatemi G, Yazici Y. Ocular Involvement of Behçet's Syndrome: a Comprehensive Review. 
Clin Rev Allergy Immunol 2015; 49(3):298-306. doi: 10.1007/s12016-014-8425-z.

27. Davatchi F, SadeghiAbdollahi B, Shams H, Shahram F, Nadji A, Chams-Davatchi C, et al. Combination of pulse cyclophosphamide and azathioprine in ocular manifestations of Behcet's disease: longitudinal study of up to 10 years. Int J Rheum Dis 2014; 17(4):444-52. doi: 10.1111/1756-185X.12248.

28. Lopez-Gonzalez R, Loza E, Jover JA, Benitez Del Castillo JM, Mendez R, Hernandez-Garcia C, et al. Treatment of refractory posterior uveitis with infliximab: a 7-year follow-up study. Scand J Rheumatol 2009; 38(1):58-62. doi: 10.1080/03009740802366076.

29. van Vollenhoven RF, Klareskog L. Infliximab dosage and infusion frequency in clinical practice: experiences in the Stockholm biologics registry STURE. Scand J Rheumatol 2007; 36(6): 418-23. doi:10.1080/03009740701416758.

30. Tugal-Tutkun I, Mudun A, Urgancioglu M, Kamali S, Kasapoglu E, Inanc M, et al. Efficacy of infliximab in the treatment of uveitis that is resistant to treatment with the combination of azathioprine, cyclosporine, and corticosteroids in Behçet's disease: an open-label trial. Arthritis Rheum 2005; 52(8): 2478-84. doi: 10.1002/art 21231.

31. Niccoli L, Nannini C, Benucci M, Chindamo D, Cassarà E, Salvarani C, et al. Long-term efficacy of infliximab in refractory posterior uveitis of Behçet's disease: a 24-month follow-up study. Rheumatology (Oxford) 2007; 46(7):1161-64. doi:10.1093/rheumatology/kem101.

32. Tabbara KF, Al-Hemidan AI. Infliximab effects compared to conventional therapy in the management of retinal vasculitis in Behcet disease. Am J Ophthalmol 2008; 146(6):845-50. doi: 10.1016/j.ajo.2008.09.010.

33. Keino H, Okada AA, Watanabe T, Nakayama M, Nakamura T. Efficacy of infliximab for early remission induction in refractory uveoretinitis associated with Behçet disease: a 2-year follow-up study. Ocul Immunol Inflamm 2017; 25(1):46-51. doi: 10.1080/09273948.2016.1239746.

34. Guzelant G, Ucar D, Esatoglu SN, Hatemi G, Ozyazgan Y, Yurdakul S, et al. Infliximab for uveitis of Behçet's syndrome: a trend for earlier initiation. Clin Exp Rheumatol 2017; 108(6):86-89.

35. Wallis RS. Reactivation of latent tuberculosis by TNF blockade: the role of interferon gamma. J Investig Dermatol Symp Proc 2007; 12(1):16-21. doi: 10.1038/sj. jidsymp.5650031.

36. Hasanreisoglu M, Cubuk MO, Ozdek S, Gurelik G, Aktas Z, Hasanreisoglu B. Interferon alpha-2a therapy in patients with refractory Behçet uveitis. Ocul Immunol Inflamm 2017; 25(1):71-75. doi: 10.3109/09273948.2015.1133835.

37. Diwo E, Gueudry J, Saadoun D, Weschler B, LeHoang P, Bodaghi B. Long-term efficacy of interferon in severe uveitis associated with Behçet disease. Ocul Immunol Inflamm 2017; 25(1):76-84. doi: 10.1080/09273948.2016.1206204.

38. Celiker H, Kazokoglu H, Direskeneli H. Factors Affecting Relapse and Remission in Behçet's Uveitis Treated with Interferon Alpha2a. J Ocul Pharmacol Ther 2019; 35(1):58-65. doi: 10.1089/jop.2018.0083.

39. Bielefeld P, Devilliers H, Deschasse C, Saadoun D, Sève $P$, Muselier A, et al. Potential of pegylated interferon alpha- 2a in Behçet uveitis: a report of five cases. Ocul Immunol Inflamm 2016; 24(5):599-602. doi: 10.3109/09273948.2015.1010652.

40. Fabiani C, Vitale A, Emmi G, Lopalco G, Vannozzi L, Guerriero S, et al. Interleukin (IL)-1 inhibition with anakinra and canakinumab in Behçet's disease-related uveitis: a multicenter retrospective observational study. Clin Rheumatol 2017; 36(1):191-97. doi: 10.1007/s10067016-3506-4.

41. Tugal-Tutkun I, Kadayifcilar S, Khairallah M, Lee SC, Ozdal P, Özyazgan Y, et al. Safety and efficacy of gevokizumab in patients with Behçet's disease uveitis: results of an exploratory phase 2 study. Ocul Immunol Inflamm 2017; 25(1):62-70. doi: 10.3109/09273948.2015.1092558.

42. Tugal-Tutkun I, Pavesio C, De Cordoue A, Bernard-Poenaru O, Gül A. Use of Gevokizumab in Patients with Behçet's Disease Uveitis: An International, Randomized, Double-Masked, Placebo-Controlled Study and Open-Label Extension Study. Ocul Immunol Inflamm 2018; 26(7):1023-33. doi: 10.1080/09273948.2017.1421233.

43. Sota J, Rigante D, Lopalco G, Frediani B, Franceschini R, Galeazzi M, et al. Biological therapies for the treatment of Behçet's disease-related uveitis beyond TNF-alpha blockade: a narrative review. Rheumatol Int 2018; 38(1):25-35. doi: 10.1007/s00296-017-3775-5.

44. Mohammadi M, Shahram F, Shams H, Akhlaghi M, Ashofteh F, Davatchi F. High-dose intravenous steroid pulse therapy in ocular involvement of Behcet's disease: a pilot double-blind controlled study. Int J Rheum Dis 2017; 20(9):1269-76. doi: 10.1111/1756-185X.13095.

45. Atienza-Mateo B, Calvo-Río V, Beltrán E, Martínez-Costa L, Valls-Pascual E, Hernández-Garfella M, et al. Anti-interleukin 6 receptor tocilizumab in refractory uveitis associated with Behçet's disease: multicentre retrospective study. Rheumatology (Oxford) 2018; 57(5):856-64. doi: 10.1093/rheumatology/kex480.

46. Dick AD, Tugal-Tutkun I, Foster S, Zierhut M, Melissa Liew SH, Bezlyak V, et al. Secukinumab in the treatment of noninfectious uveitis: results of three randomized, controlled clinical trials. Ophthalmology 2013; 120(4):77787. doi: 10.1016/j.ophtha.2012.09.040.

47. Baerveldt EM, Kappen JH, Thio HB, van Laar JA, van Hagen PM, Prens EP. Successful long-term triple disease control by ustekinumab in a patient with Behçet's disease, psoriasis and hidradenitis suppurativa. Ann Rheum Dis 2013; 72(4):626-27. doi.org/10.1136/annrheumdis-2012-202392.

48. Buggage RR, Levy-Clarke G, Sen HN, Ursea R, Srivastava SK, Suhler EB, et al. A double masked, randomized study to investigate the safety and efficacy of daclizum$\mathrm{ab}$ to treat the ocular complications related to Behçet's disease. Ocul Immunol Inflamm 2007; 15(2):63-70. 
doi:10.1080/09273940701299370.

49. Davatchi F, Shams H, Rezaipoor M, Sadeghi-Abdollahi B, Shahram F, Nadji A, et al. Rituximab in intractable ocular lesions of Behçet's disease; randomized single blind control study (pilot study). Int J Rheum Dis 2010; 13(3):246252. doi: $10.1111 / \mathrm{j} .1756-185 X .2010 .01546 . x$.
50. Mohammad AJ, Smith RM, Chow YW, Chaudhry AN, Jayne DR. Alemtuzumab as remission induction therapy in Behçet disease: a 20-year experience. J Rheumatol 2015; 42(10):1906-13. doi: 10.3899/jrheum.141344. 